\title{
Transcriptional analysis of Clostridium beijerinckii NCIMB 8052 to elucidate role of furfural stress during acetone butanol ethanol fermentation
}

\author{
Yan Zhang and Thaddeus Chukwuemeka Ezeji
}

\begin{abstract}
Background: Furfural is the prevalent microbial inhibitor generated during pretreatment and hydrolysis of lignocellulose biomass to monomeric sugars, but the response of acetone butanol ethanol (ABE) producing Clostridium beijerinckii NCIMB 8052 to this compound at the molecular level is unknown. To discern the effect of furfural on C. beijerinckii and to gain insight into molecular mechanisms of action and detoxification, physiological changes of furfural-stressed cultures during acetone butanol ethanol (ABE) fermentation were studied, and differentially expressed genes were profiled by genome-wide transcriptional analysis.

Results: A total of 5,003 C. beijerinckii NCIMB 8052 genes capturing about 99.7\% of the genome were examined. About 111 genes were differentially expressed (up- or down-regulated) by C. beijerinckii when it was challenged with furfural at acidogenic growth phase compared with 721 genes that were differentially expressed (up- or down-regulated) when C. beijerinckii was challenged with furfural at solventogenic growth phase. The differentially expressed genes include genes related to redox and cofactors, membrane transporters, carbohydrate, amino sugar and nucleotide sugar metabolisms, heat shock proteins, DNA repair, and two-component signal transduction system. While C. beijerinckii exposed to furfural stress during the acidogenic growth phase produced 13\% more ABE than the unstressed control, ABE production by C. beijerinckii ceased following exposure to furfural stress during the solventogenic growth phase.

Conclusion: Genome-wide transcriptional response of $C$. beijerinckii to furfural stress was investigated for the first time using microarray analysis. Stresses emanating from ABE accumulation in the fermentation medium; redox balance perturbations; and repression of genes that code for the phosphotransferase system, cell motility and flagellar proteins (and combinations thereof) may have caused the premature termination of C. beijerinckii 8052 growth and ABE production following furfural challenge at the solventogenic phase.This study provides insights into basis for metabolic engineering of C. beijerinckii NCIMB 8052 for enhanced tolerance of lignocellulose-derived microbial inhibitory compounds, thereby improving bioconversion of lignocellulose biomass hydrolysates to biofuels and chemicals. Indeed, two enzymes encoded by Cbei_3974 and Cbei_3904 belonging to aldo/keto reductase (AKR) and short-chain dehydrogenase/reductase (SDR) families have been identified to be involved in furfural detoxification and tolerance.
\end{abstract}

Keywords: Furfural toxicity, Furfural tolerance, Acetone, Microarray, Real time PCR

\footnotetext{
* Correspondence: ezeji.1@osu.edu

The Ohio State University, Department of Animal Sciences and Ohio

Agricultural Research and Development Center (OARDC), 305 Gerlaugh Hall,

1680 Madison Avenue, Wooster OH 44691, USA
} 


\section{Introduction}

Clostridium species are gram positive, anaerobic, sporeforming bacteria [1]. Production of ABE (acetone-butanolethanol) by solventogenic Clostridium species is attractive by virtue of their ability to utilize sugars such as cellobiose, glucose, xylose, arabinose and mannose that are present in lignocellulosic biomass hydrolysate. Butanol production from lignocellulosic biomass has shown promise, and the feedstock is abundant, renewable and relatively cheap [2]. However, microbial inhibitors, such as furfural, hydroxymethylfurfural (HMF), hydroxybenzaldehyde, and coumaric acid, are produced during lignocellulosic biomass pretreatment and these compounds impede biofuel production from generated hydrolysates [2].

These lignocellulose-derived inhibitory compounds inhibit microbial cell growth and biofuel production by disrupting cell membranes, damaging polynucleotides, repressing central metabolic enzymes, decreasing intracellular $\mathrm{pH}$, increasing cell turgor pressure, and inducing oxidative stress [3,4]. Although physical, chemical and biological inhibitor removal methods may facilitate substrate utilization and butanol fermentation, removal of inhibitors from hydrolysates prior to fermentation may not be economically feasible due to the cost associated with additional processing steps and the potential loss of fermentable sugars [5]. To make bioconversion of lignocellulosic biomass to butanol economically feasible, development of an inhibitor-tolerant strain of bacteria is crucial. Previous studies have investigated the impact of lignocellulose-derived inhibitors on butanol fermentation. Ezeji et al. [2] have demonstrated the inhibitory effect of corn-fiber-derived aldehyde, organic acid and phenolic compounds on cell growth and ABE production by $C$. beijerinckii BA101, and they have shown the synergistic effect of mixtures of inhibitors over the sum of individual toxic effects. Chemicals present in wheat straw hydrolysates, mainly furfural and HMF, have also been reported to enhance butanol productivity when using C. beijerinckii P260 [6]. Furthermore, the detoxification of furfural and HMF by C. acetobutylicum ATCC 824 has been shown during butanol fermentation [7]. However, the underlying mechanisms for inhibitor detoxification and tolerance by fermenting solventogenic Clostridium species remain unclear. This gap in knowledge continues to hamper attempts at engineering inhibitor-tolerant bacterial strains, as evidenced by the persistent low butanol productivity from biomass feedstock and, hence, the high cost of butanol production.

The objective of this study was to examine the response of $C$. beijerinckii NCIMB 8052 at the mRNA level to the challenge of furfural to better understand the interplay of furfural toxicity and corresponding bacterial tolerance mechanisms. The impact of furfural, the most representative lignocellulose-derived inhibitor, on
C. beijerinckii NCIMB 8052 was studied to understand its potential mechanism and that of other lignocellulosederived aldehydes. To gain insight into mechanisms of furfural toxicity and tolerance, the interactive effect of furfural conversion and ABE production was studied by challenging fermentation cultures with different doses of furfural at different growth stages. To examine physiological alterations in C. beijerinckii NCIMB 8052 cell growth and $\mathrm{ABE}$ production as a consequence of furfural stress, gene expression patterns between control and furfural-stressed treatment cultures were compared by genome-wide transcriptional microarray analysis. The comparison of gene expression patterns in relation to $\mathrm{ABE}$ production is expected to provide insights toward metabolically engineering C. beijerinckii NCIMB 8052 with enhanced tolerance for lignocellulose-derived microbial inhibitory compounds and better utilization of lignocellulosic biomass hydrolysates.

\section{Results}

Why microarray analysis of C. beijerinckii 8052

transcriptome under furfural stress?

Furfural was chosen as archetypical lignocellulose-derived inhibitory compound for this investigation because it is the most prevalent microbial inhibitor generated during pretreatment and hydrolysis of lignocellulosic biomass to monomeric sugars. However, furfural has been shown previously to enhance solventogenic C. beijerinckii BA101 growth and $\mathrm{ABE}$ production when the fermentation medium was supplemented with $<3 \mathrm{~g} / \mathrm{L}$ furfural prior to fermentation $[2,8]$. To better understand mechanisms with which furfural affect $C$. beijerinckii 8052 physiology, the global response of $C$. beijerinckii 8052 to the challenge of furfural during both acidogenesis and solventogenesis at the mRNA level was profiled using whole genome microarray analysis. The findings from the present study are grouped into different attributes.

\section{Expression of C. beijerinckii 8052 redox and cofactor genes in the presence of furfural}

After the challenge of furfural during the acidogenic phase some genes expressing redox proteins in $C$. beijerinckii 8052 increased by up to 16 -fold compared with that in the control group (Figure 1A and Additional file 1: Table S4A). Gene ontology (GO) analysis (Additional file 2: Table S2A) shows that three of these redox proteins are involved in antioxidant activity (GO:0016209): thioredoxin reductase (Cbei_2681), redoxin domain-containing protein (Cbei_2680), and glutathione peroxidase (Cbei_0389); the latter two possess oxidoreductase activity acting on peroxide as an acceptor (GO:0016684) and in response to oxidative stress (GO:0006979). Another group of genes that was up-regulated by more than threefold encodes oxidoreductases acting on $\mathrm{CH}$ or $\mathrm{CH} 2$ groups, with disulfide 


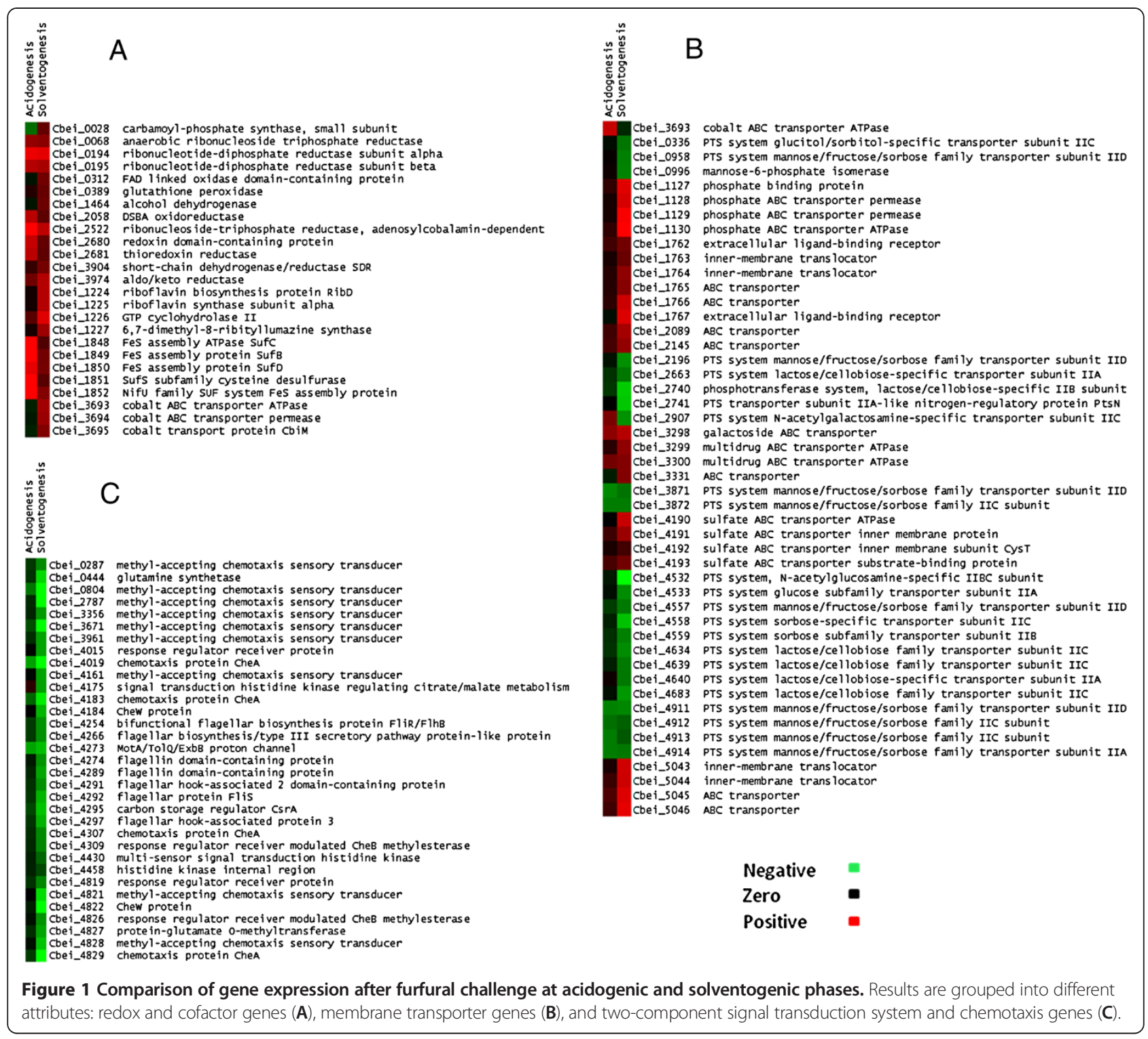

as an acceptor (GO:0016728) (Additional file 2: Table $\mathrm{S} 2 \mathrm{~A})$. According to KEGG enrichment pathway analysis, this group of genes is associated with purine (cbe00230) and pyrimidine (cbe00240) metabolisms (Additional file 3: Table S3), and includes anaerobic ribonucleoside triphosphate reductase (Cbei_0068), adenosylcobalamindependent ribonucleoside-triphosphate reductase (Cbei 2522), and ribonucleotide-diphosphate reductase subunits (Cbei_0194 and Cbei_0195). The remaining oxidoreductases (GO:0016491) (Additional file 2: Table S2A) that had higher expression in the furfural treatment culture than in the control culture are aldo/keto reductase (Cbei_ 3974), short-chain dehydrogenase/reductase (SDR) (Cbei_ 3904), DSBA oxidoreductase (Cbei_2058), FAD linked oxidase domain-containing protein (Cbei_0312), and alcohol dehydrogenase (Cbei_1464) (Figure 1A and Additional file 1: Table S4A). The transcriptome of $C$. beijerinckii 8052 after furfural challenge at the solventogenic phase shows some similarities in terms of redox enzymes. All the above genes, except FAD linked oxidase domaincontaining protein (Cbei_0312), and alcohol dehydrogenase (Cbei_1464), were also induced by furfural challenge at the solventogenic phase (Figure 1A and Additional file 1: Table S4C).

Besides redox enzymes, components associated with redox reactions were also highly expressed in cultures challenged with furfural at the acidogenic phase. One of the related components affected by furfural treatment is the iron-sulfur cluster. The expression of genes encoding ironsulfur cluster assembly proteins (Cbei_1848, Cbei_1849, Cbei_1850, Cbei_1851 and Cbei_1852) increased by up to fivefold (Figure 1A and Additional file 1: Table S4A); these 
genes are classified into the cofactor biosynthetic process (GO:0051188) (Additional file 2: Table S2A). Another group of genes classified into the same group (GO:0051188), as well as into the vitamin biosynthetic process (GO:0009110) (Additional file 2: Table S2A), includes those encoding cobalt ABC transporter ATPase (Cbei_3693), cobalt ABC transporter permease (Cbei_3694) and cobalt transport protein CbiM (Cbei_3695) (Figure 1A and Additional file 1: Table S4A). In addition, differential expression was also observed in furfural-challenged cultures for several members of riboflavin biosynthesis genes (Cbei_1224, Cbei_1225, Cbei_1226, Cbei_1227) (Figure 1A and Additional file 1: Table S4A). This group of genes belongs to the Gene Ontology term riboflavin metabolic process (GO:0006771) (Additional file 2: Table S2A), and if classified by KEGG pathway analysis, these genes are involved in riboflavin metabolism (cbe00740) (Additional file 3: Table S3). However, furfural challenge during solventogenesis affected gene expression differently from that at acidogenesis in terms of redox enzyme cofactors. First, expression of genes that code for iron-sulfur cluster assembly proteins was even higher during solventogenesis (Figure 1A and Additional file 1: Table S4C), and those genes (Cbei_1848, Cbei_1849, Cbei_ 1850, Cbei_1851 and Cbei_1852) were up-regulated in furfural-challenged cultures by up to 54-fold compared to no more than fivefold during acidogenesis (Figure 1A and Additional file 1: Table S4C). On the other hand, the expression of genes involved in synthesis of other cofactors, including riboflavin and cobalamin, did not show obvious alterations during furfural challenge at solventogenesis (Figure 1A), although these genes were highly induced during furfural challenge at acidogenesis (Figure 1A and Additional file 1: Table S4A).

\section{Expression of membrane transporter genes in $C$. beijerinckii 8052}

Gene expression analysis of C. beijerinckii 8052 responding to furfural stress during butanol fermentation was performed to determine not only the effect of furfural on $C$. beijerinckii 8052 growth and $\mathrm{ABE}$ production but also on molecular physiological changes. Furfural in the ABE fermentation medium altered expressions of the membrane transport system, including ATP-binding cassette transporters (ABC-transporter) and phosphotransferase system (PTS), in C. beijerinckii 8052 during both acidogenic and solventogenic phases (Figure 1B). While some ABCtransporter genes such as galactoside $\mathrm{ABC}$ transporter (Cbei_3298), multidrug ABC transporter ATPase (Cbei_ 3299 and Cbei_3300), and cobalt ABC transporter ATPase (Cbei_3693) were expressed up to sevenfold in furfuralchallenged C. beijerinckii 8052 at the acidogenic phase (Figure 1B and Additional file 1: Table S4A), expression of these transporter genes was increased by a greater fold during the solventogenic phase (Figure 1B and Additional file 1: Table S4C). According to KEGG pathway analysis, some $\mathrm{ABC}$-transporter-related genes may be classified into what is known as KEGG pathway $\mathrm{ABC}$ transporters (cbe02010) (Additional file 3: Table S3), which include transport proteins that catalyze transmembrane movement of different substrates including sulfate, phosphate and branched-chain amino acid. Expression of these genes increased up to twelvefold in furfural-challenged $C$. beijerinckii 8052 during solventogenesis (Figure 1B and Additional file 1: Table S4C). Specifically, genes involved in sulfate transportation include sulfate $A B C$ transporter ATPase (Cbei_4190), sulfate ABC transporter inner membrane protein (Cbei_4191 and Cbei_4192), and sulfate $\mathrm{ABC}$ transporter substrate-binding protein (Cbei_4193); phosphate transporters include phosphate binding protein (Cbei_1127), phosphate ABC transporter permease (Cbei_ 1128 and Cbei_1129), and phosphate ABC transporter ATPase (Cbei_1130); and genes that code for branchedchain amino acids include extracellular ligand-binding receptor (Cbei_1762, Cbei_1767 and Cbei_5042), innermembrane translocator (Cbei_1763, Cbei_1764, Cbei_5043, and Cbei_5044), and ABC transporter (Cbei_1765, Cbei_ 1766, Cbei_5045, Cbei_5046, and Cbei_2145). In addition, genes for cyanate or nitrite transportation that belong to ABC transporters (Cbei_2089 and Cbei_3331) are equally induced in furfural-challenged C. beijerinckii 8052 during solventogenesis (Figure $1 \mathrm{~B}$ and Additional file 1: Table S4C).

Unlike $\mathrm{ABC}$-transporter genes whose expressions were increased by furfural-challenged C. beijerinckii 8052, another member of the membrane transporter system, phosphotransferase system (PTS), was repressed in furfural-challenged cultures of C. beijerinckii 8052 at both acidogenic and solventogenic phases (Figure 1B). Prominent among the PTS are the PTS system mannose/ fructose/sorbose family transporters involved in fructose and mannose metabolism (cbe00051) and amino sugar and nucleotide sugar metabolism (cbe00520) (Additional file 3: Table S3). While mostly genes encoding PTS system mannose/fructose/sorbose family transporter subunits IIA (Cbei_4914), IIB (Cbei_4913), IIC (Cbei_4912 and Cbei_ 3872), and IID (Cbei_4911 and Cbei_3871) were repressed by up to fourfold when cultures of C. beijerinckii 8052 were challenged with furfural during the acidogenic growth phase (Figure 1B and Additional file 1: Table S4B), a wider spectrum of genes, including PTS system mannose/fructose/sorbose family transporters, was repressed when cultures of $C$. beijerinckii 8052 were challenged with furfural at the solventogenic growth phase (Figure $1 \mathrm{~B}$ and Additional file 1: Table S4D). The repressed genes associated with sugar metabolism during the solventogenic growth phase include mannose/fructose/sorbose family transporter subunit IID (Cbei_0958, Cbei_2196, Cbei_ 3871, Cbei_4557, and Cbei_4911), mannose/fructose/ 
sorbose family IIC subunit (Cbei_3872), sorbose-specific transporter subunit IIC (Cbei_4558), sorbose subfamily transporter subunit IIB (Cbei_4559), mannose-6-phosphate isomerase (Cbei_0996), and glucitol/sorbitol-specific transporter subunit IIC (Cbei_0336) (Figure 1B). Besides the listed genes, $\mathrm{N}$-acetylglucosamine-specific IIBC subunit (Cbei_4532) and glucose subfamily transporter subunit IIA (Cbei_4533) are also involved in amino sugar and nucleotide sugar metabolism (cbe00520) (Additional file 3: Table S3). The repression of these genes may affect the transportation and metabolism of sugars such as those in the glucose family ( $\mathrm{N}$-acetyl-D-glucosamine, D-glucosamine and glucosides), the lactose and cellobiose families, the mannose family (mannose and galactosamine), and others such as sorbose, sorbitol, glucitol, and L-ascorbate, many of which are monomeric sugars of lignocellulosic biomass. Furfural challenge of $C$. beijerinckii 8052 during the solventogenic phase, in addition, inhibited other specific PTS systems, including lactose/cellobiosespecific subunits (Cbei_2663, Cbei_2740, Cbei_4634, Cbei_ 4639, Cbei_4640, and Cbei_4683), sorbose-specific subunits (Cbei_2907) and subunit IIA-like nitrogen-regulatory protein PtsN (Cbei_2741) (Figure 1B and Additional file 1: Table S4D).

\section{Expression of a two-component signal transduction system, chemotaxis, and cell motility genes in $C$. beijerinckii 8052}

As with membrane transporter genes, the expression of genes associated with the two-component signal transduction system (cbe02020) was altered in furfural-challenged C. beijerinckii 8052 at both acidogenic and solventogenic phases (Additional file 3: Table S3). Following furfural challenge of $\mathrm{C}$. beijerinckii 8052 during the acidogenic growth phase, only two genes (Cbei_4019, chemotaxis protein CheA and Cbei_4273, MotA/TolQ/ExbB proton channel) involved in the coding of two-component signal transduction system were repressed by about fourfold (Figure $1 \mathrm{C}$ and Additional file 1: Table S4B). When the C. beijerinckii 8052 culture was challenged with furfural at the solventogenic growth phase, more than 40 genes were repressed by up to 18-fold (Figure $1 \mathrm{C}$ and Additional file 1: Table S4D). Notably, the two major functional categories of genes belonging to the two-component signal transduction system are bacterial chemotaxis (cbe02030) and flagellar assembly (cbe02040) (Additional file 3: Table S3).

Although chemotaxis is the most widely studied twocomponent sensory system in bacteria, not much has been reported about the system in relation to furfural stress in solventogenic Clostridium species. When the $C$. beijerinckii 8052 culture was challenged with furfural at the solventogenic growth phase, many genes associated with the chemotaxis sensory system in C. beijerinckii 8052, such as methyl-accepting chemotaxis sensory transducer
(Cbei_0287, Cbei_0804, Cbei_2787, Cbei_3356, Cbei_3671, Cbei_3961, Cbei_4161, Cbei_4821, and Cbei_4828) and genes that code for chemotaxis proteins (CheA Cbei_4307, Cbei_4829, and Cbei_4183; CheB Cbei_4309 and Cbei_ 4826; CheR Cbei_4827; CheW Cbei_4184 and Cbei_4822; CheY Cbei_4819 and Cbei_4015; and MotA Cbei_4273), were differentially repressed (Figure $1 \mathrm{C}$ and Additional file 1: Table S4D). Since chemotaxis directs flagellar motion and controls the swimming pattern of the cell [9], genes encoding flagellar assembly proteins were also differentially repressed by furfural. These flagellar proteins include FliS (Cbei_4292), FliR/FlhB (Cbei_4254), FliH (Cbei_4266), MotA (Cbei_4273), FlgL (Cbei_4297), FliC (Cbei_4274 and Cbei_4289), and FliD (Cbei_4291), as shown in Figure $1 \mathrm{C}$ and Additional file 1: Table S4D. Additionally, there are two-component signal transduction systems related to genes encoding proteins that partake in many cellular functions such as quorum sensing and flagella assembly (flagellin domain-containing protein Cbei_ 4274 and Cbei_4289, and MotA/TolQ/ExbB proton channel Cbei_4273), carbon storage regulation (carbon storage regulator CsrA Cbei_4295), nitrogen assimilation (glutamine synthetase Cbei_0444), and cell cycle progression and development (signal transduction histidine kinase regulating citrate/malate metabolism Cbei_4175, multisensor signal transduction histidine kinase Cbei_4430, and histidine kinase internal region Cbei_4458) that were differentially repressed when the C. beijerinckii 8052 culture was challenged with furfural at the solventogenic growth phase (Figure 1C and Additional file 1: Table S4D).

\section{Validation of gene expression data from microarray analysis by Q-RT-PCR}

To validate differential gene expressions obtained using microarray analysis, Q-RT-PCR was applied to quantify gene expression levels in biological replicate cultures of $C$. beijerinckii 8052 using treatment conditions that mimicked microarray treatment but were independent of the cultures used for microarray analysis. Briefly, the C. beijerinckii 8052 culture was challenged with furfural at acidogenic and solventogenic growth phases during which 19 and 23 genes, respectively, were evaluated. The genes were selected randomly within each range of fold change. Differential gene expressions in furfural-challenged C. beijerinckii 8052 determined via microarray analysis and Q-RT-PCR were found to have a high degree of correlation between them at both acidogenic $(\mathrm{R}=0.87)$ and solventogenic phases $(\mathrm{R}=0.84)$ (Figure 2, Additional file 4: Table S1).

\section{Interactive effect of furfural reduction and ABE production}

To determine effects of furfural on C. beijerinckii 8052 growth and $\mathrm{ABE}$ production at acidogenic and solventogenic phases, a C. beijerinckii 8052 culture grown in P2 medium was challenged with furfural, and changes in cell 


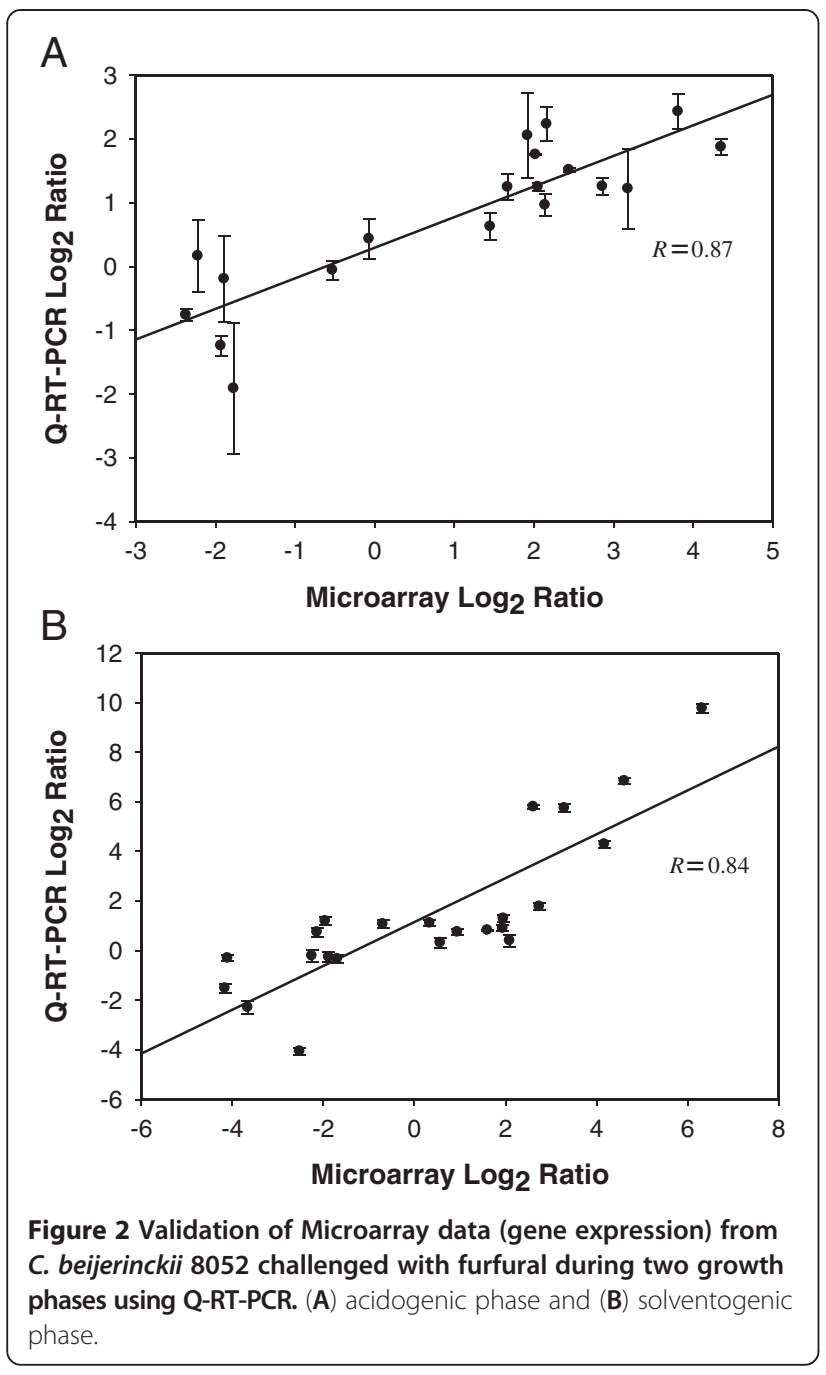

density, acid production and ABE production were measured relative to cultures grown in P2 medium without furfural. Challenge of C. beijerinckii 8052 with $2 \mathrm{~g} / \mathrm{L}$ furfural during the acidogenic phase (fermentation time $8 \mathrm{~h}$ ) when $\mathrm{OD}_{600}$ was between 1.5 and 2.0 resulted in complete depletion of furfural within $4 \mathrm{~h}$, and cell densities of the furfuralchallenged C. beijerinckii 8052 and control cultures were nearly indistinguishable (Figure 3A). However, acetone and butanol production by furfural-challenged $C$. beijerinckii 8052 only increased by 1.1- and 1.2-fold, respectively, during the period, compared to 1.3- and 2.7-fold increases in acetone and butanol production, respectively, by the control culture (Figure 3A-E). The acetic and butyric acid levels measured in both the furfural-challenged $C$. beijerinckii 8052 and the unchallenged control cultures were reflective of the respective acetone and butanol production profiles (Figure 3). Notably, although ABE production and acid reassimilation by furfural-challenged $C$. beijerinckii 8052 were inferior to that of the unchallenged control, the fermentation proceeded rapidly following depletion of furfural, and the maximum concentrations of acetone, butanol, and ethanol produced by the furfural-challenged $C$. beijerinckii 8052 were higher than that of the control by $28 \%, 2 \%$ and $6 \%$, respectively (Figure 4A-C). Interestingly, acid assimilation was stimulated in the furfural-challenged $C$. beijerinckii 8052 following furfural depletion in the fermentation medium, and the final concentrations of acetic and butyric acid were lower than that of the control by $22 \%$ and $19 \%$, respectively (Figure $4 \mathrm{D}$ and E).

While C. beijerinckii 8052 cultures challenged with furfural at the acidogenic phase could tolerate furfural and produce more $\mathrm{ABE}$ than the control following the depletion of furfural, challenging C. beijerinckii 8052 culture with furfural during the solventogenic phase (fermentation time $25 \mathrm{~h} ; \mathrm{OD}_{600}$ 5.0-5.5) resulted in shut down of ABE production and rapid accumulation of acetic and butyric acid in the fermentation medium (Figure 5). Unlike the control, C. beijerinckii 8052 grown in P2 medium without furfural underwent a normal fermentation process (Figures 5 and 6). At solventogenesis, furfural reduction was impeded (Figure 5G) when concentrations of acetone, ethanol and butanol were high $(3.40 \mathrm{~g} / \mathrm{L} \pm 0.27 \mathrm{~g} / \mathrm{L}, 0.22 \mathrm{~g} / \mathrm{L} \pm 0.02 \mathrm{~g} / \mathrm{L}$, and $5.93 \mathrm{~g} / \mathrm{L} \pm 0.12 \mathrm{~g} / \mathrm{L}$, respectively) (Figure $5 \mathrm{~B}$ and $\mathrm{C}$ ). Although the cell density of $C$. beijerinckii 8052 in the solventogenic phase culture was four times higher than in the acidogenic phase culture, $3 \mathrm{~g} / \mathrm{L}$ furfural was reduced by only $80 \%$ in $4 \mathrm{~h}$ (Figure 5G). To further evaluate the effect of challenging C. beijerinckii 8052 at the solventogenic phase with $3 \mathrm{~g} / \mathrm{L}$ furfural, the fermentation was allowed to proceed for another $40 \mathrm{~h}$ during which no further growth and reduction of furfural were observed (data not shown); and uptake of acetic and butyric acid by $C$. beijerinckii 8052 did not occur (Figure 6). Similarly, when $2 \mathrm{~g} / \mathrm{L}$ furfural was used to challenge $C$. beijerinckii 8052 at the solventogenic phase, the $2 \mathrm{~g} / \mathrm{L}$ furfural was depleted before $2 \mathrm{~h}$. However, ABE production was shut down (Figure 7A-C) followed by accumulation of acetic and butyric acids (Figure 7D-E) in the fermentation medium, and the culture did not recover following the depletion of furfural.

To independently verify whether the presence of $A B E$ in the fermentation medium was contributing to the toxicity of furfural to C. beijerinckii 8052 and decreasing furfural reduction during the solventogenic phase, the acidogenic phase culture of C. beijerinckii 8052 was supplemented with $2 \mathrm{~g} / \mathrm{L}$ furfural together with acetone, ethanol and butanol at concentrations that mimic their concentration at the solventogenic phase. Interestingly, this situation reduced the concentration of furfural in the fermentation medium by only $75 \%$ after $4 \mathrm{~h}$ post-furfural challenge, unlike the control without $\mathrm{ABE}$ supplementation, which depleted the furfural in $3 \mathrm{~h}$ (Figure 8). However, the presence of furfural in the fermentation medium during the solventogenic growth phase did not have remarkable impact on the expression of $\mathrm{ABE}$ production genes in C. beijerinckii 8052 (Additional file 5: Table S5). 

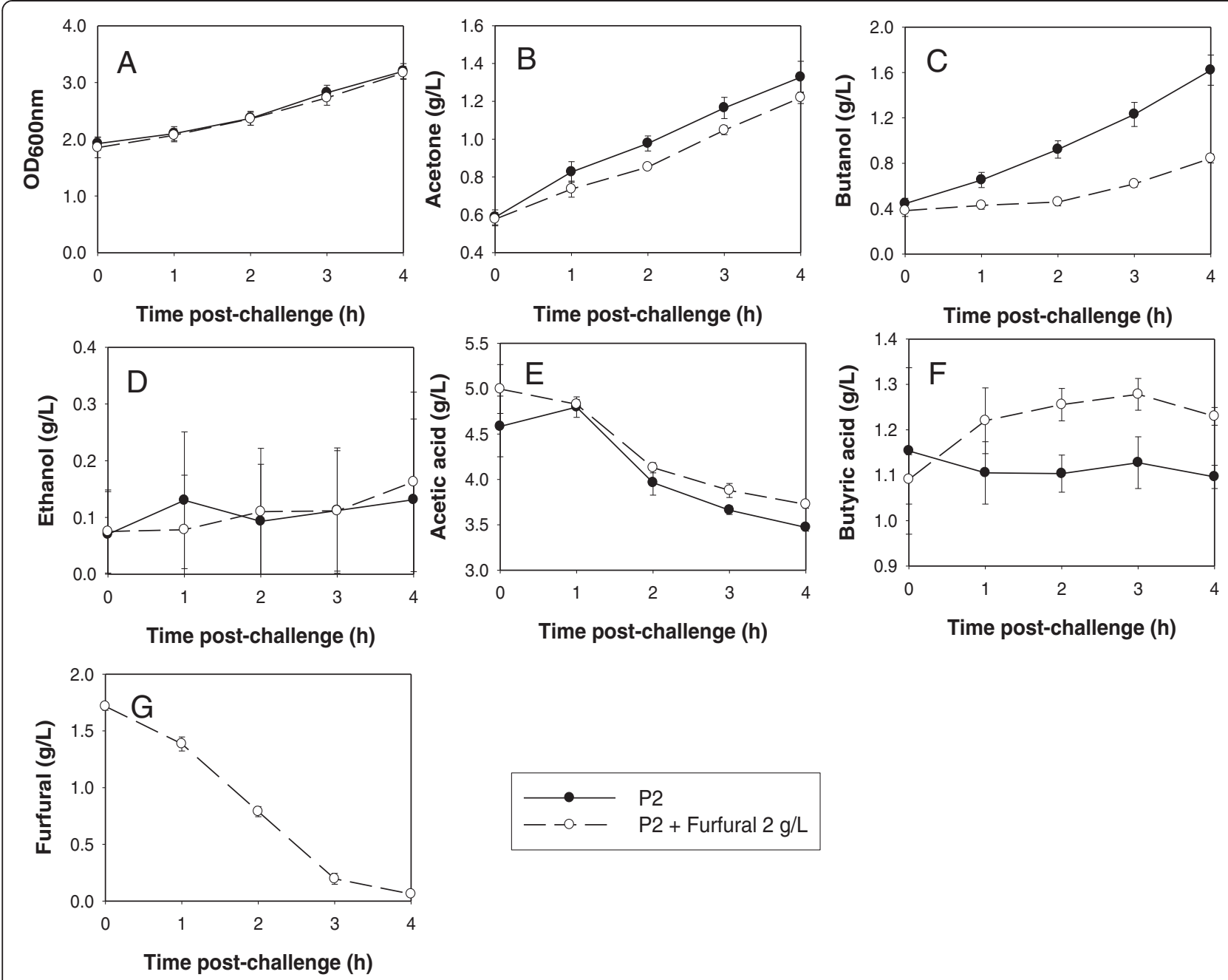

Figure 3 Cell growth, ABE production and furfural reduction after challenging C. beijerinckii 8052 with furfural at the acidogenic phase. Following $8 \mathrm{~h}$ of $\mathrm{C}$. beijerinckii 8052 growth in P2 medium, the fermentation broth was distributed into two groups. Each group was made up of 3 aliquots. One group was challenged with $2 \mathrm{~g} / \mathrm{L}$ furfural (treatment) and the other was left unchallenged (control), followed by anaerobic incubation at $35^{\circ} \mathrm{C}$ for $4 \mathrm{~h}$ during which samples were collected every hour for analysis. Quantified parameters include cell growth (A), acetone (B), butanol (C), ethanol (D), acetic acid (E), butyric acid (F), and residual furfural (G).

\section{Discussion}

While inhibitory properties of degradation products of lignocellulosic biomass are widely recognized as a major limitation to bioconversion of biomass to biofuels and chemicals [5], the gap in knowledge with respect to detoxification of these lignocellulose-derived inhibitory compounds by fermenting microorganisms continues to impede the development of inhibitor-tolerant strains vis-à-vis commercialization of biofuels. This study presents the physiological changes and transcriptional responses of C. beijerinckii NCIMB 8052 to furfural challenge at different growth and fermentation stages, highlighting a systematic pattern of gene regulations and revealing potential target genes for strain improvements by genetic engineering.
Genome-wide microarray analysis demonstrated a clear perspective on the effect of the lignocellulosic biomassderived inhibitor furfural on the transcriptional profile of C. beijerinckii 8052. This study revealed for the first time that changes in physiological activities of furfuralchallenged cultures of $C$. beijerinckii are coordinated with transcriptional variations during $\mathrm{ABE}$ fermentation. Validation of microarray data by Q-RT-PCR using samples from independent biological treatment showed high degrees of correlation coefficient $(\mathrm{R})$ at both acidogenic and solventogenic phases ( 0.87 and 0.84 , respectively), which fall into the upper values of the reported range $(-0.48$ to + 0.93) [10], thus, confirming strong reliability of data obtained by microarray analysis. This result is significant because the correlation coefficient is the generally accepted 


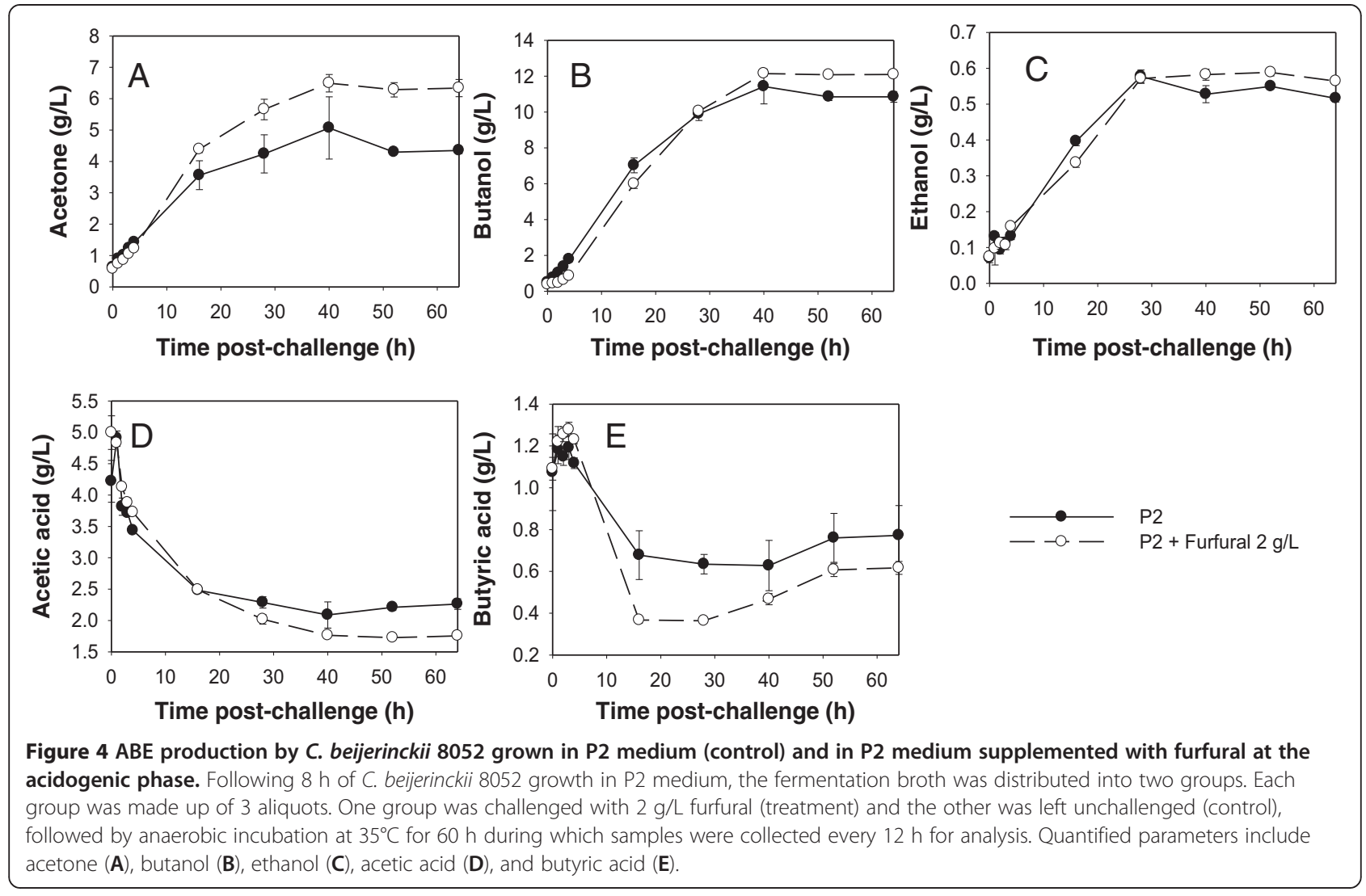

criterion for assessing reliability of microarray data [11]. Ramifications of obtained results are discussed below under different attributes.

Redox and cofactor genes are crucial for detoxification of furfural by C. beijerinckii 8052

Furfural challenge increases the expression of genes encoding redox proteins in C. beijerinckii 8052 (Figure 1A and Additional file 1: Table S4A and S4C). Differential expression of redox genes involved in antioxidant activity suggests that furfural causes oxidative stress in $C$. beijerinckii 8052 . In yeast, furfural induces the accumulation of reactive oxygen species (ROS), that are known to damage DNA, lipids and proteins and that subsequently induce programmed cell death [4]. Glutathione peroxidases and thioredoxin peroxidases, which were differentially induced in furfural-challenged C. beijerinckii 8052 (Figure 1A and Additional file 1: Table S4A and S4C), can reduce $\mathrm{H}_{2} \mathrm{O}_{2}$ to $\mathrm{H}_{2} \mathrm{O}$ via oxidation of thiol groups. The reduction of oxidized glutathione and thioredoxin is catalyzed by glutathione reductase or thioredoxin reductase, respectively, using NADPH as the electron donor [12]. Thioredoxin and glutathione can also function as oxygen quenchers and hydroxyl radical scavengers [13-15]. Given that this study was conducted in an anaerobic chamber with less than $1 \mathrm{ppm}$ of molecular oxygen (monitored by an oxygen detector), the origin of ROS is not clear. However, production of ROS, hydroperoxide or other radical species by anaerobes has been hypothesized and elucidated previously $[16,17]$. Organic hydroperoxide generated under anaerobic condition, therefore, may induce the expression of alkyl hydroperoxide reductase gene in E. coli [17], and glutathione peroxidase and thioredoxin peroxidase genes in C. beijerinckii 8052. Another gene encoding a thioredoxin family protein dsbA oxidoreductase, a periplasmic oxidoreductase that facilitates disulfide bond formation in proteins, was found in this study to be induced by furfural. Overexpression of dsbA in E. coli increased soluble protein level in the periplasm and improved enzyme secretion and activity [18]. Elevated levels of antioxidant activity due to furfural challenge indicate increased oxidative stress, thus, accentuating innate detoxification capabilities of $C$. beijerinckii under the influence of furfural stress. Additionally, thioredoxin and thioredoxin reductase work in tandem with ribonucleotide reductase during reduction of ribonucleoside diphosphates to deoxyribonucleoside diphosphates [19]. The induced expression of these redox enzymes (Figure $1 \mathrm{~A}$ and Additional file 1: Table S4A) involved in purine and pyrimidine metabolism in C. beijerinckii 8052 (Additional file 3: Table S3) suggests greater demand of nucleotides due to furfural stress. This premise is supported by the fact that DNA 


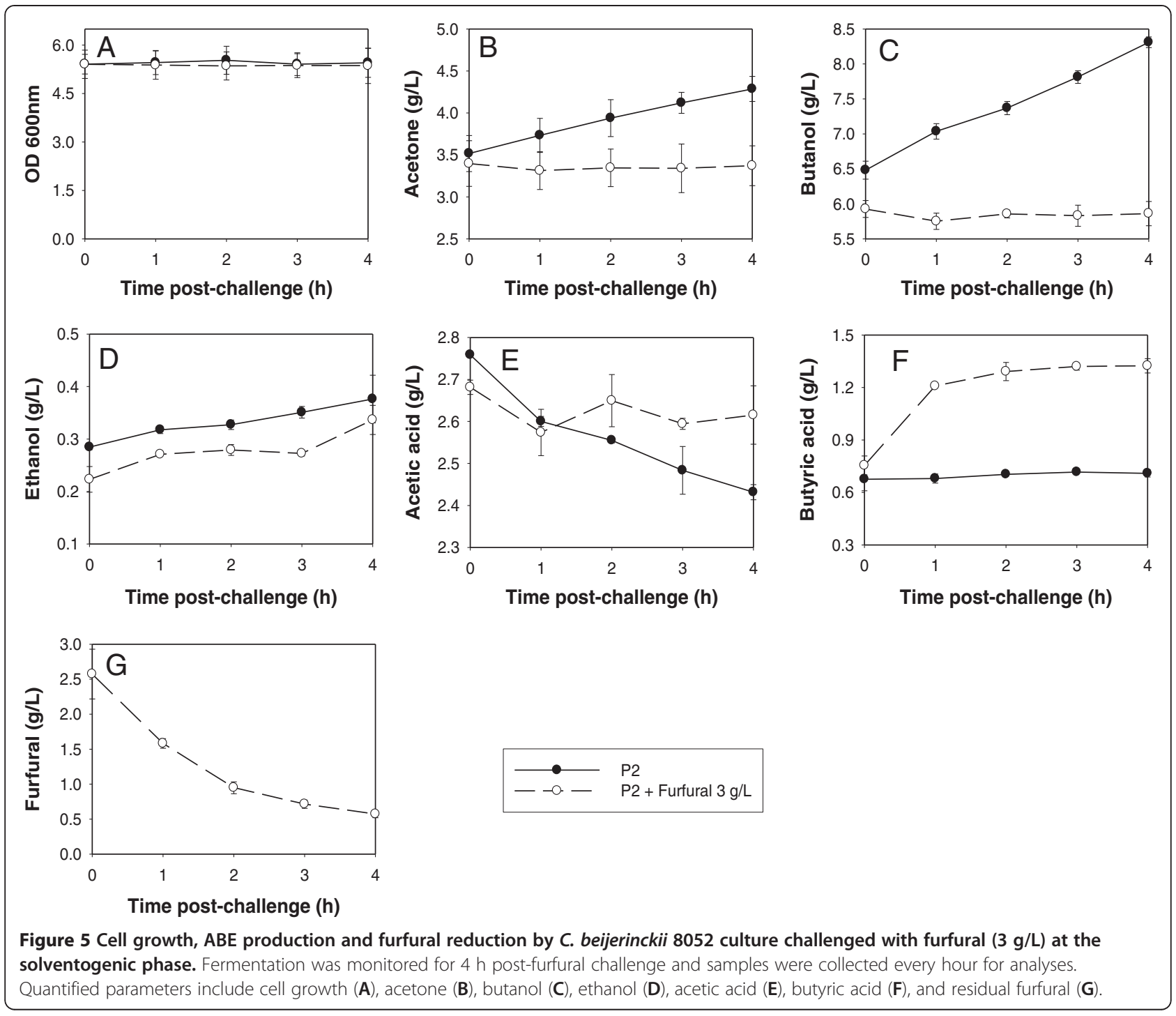

molecules are prone to damage in the presence of furfural [3], and in this case, DNA repair or biosynthesis is activated leading to induced expression of redox enzymes.

The differentially induced genes encoding oxidoreductases such as aldo/keto reductase (AKR) and short-chain dehydrogenase/reductase (SDR) in C. beijerinckii, which are involved in the reduction of furfural to furfuryl alcohol, have been reported elsewhere as scavengers of furfural in Escherichia coli [20,21], Saccharomyces cerevisiae [22], and Zymomonas mobilis [23] fermentations. Direct reduction of furfural to the less toxic furfuryl alcohol [7] is another strategy C. beijerinckii 8052 uses to mitigate toxic effects of furfural.

Moreover, differential expression of genes encoding the iron-sulfur cluster and cobalamin- and riboflavin-associated proteins, was observed in furfural-challenged $C$. beijerinckii 8052 (Figure 1A and Additional file 1: Table S4A), thus, accentuating cellular responses to furfural stress by redox balancing because these proteins require cofactors such as NADH and NADPH to facilitate catalysis. Notably, the iron-sulfur cluster plays important roles in electron transfer by redox enzymes, disulfide reduction by ferredoxin:thioredoxin reductase, regulation of gene expressions associated with Ferredoxin-NADP ${ }^{+}$reductase, and iron and sulfur storage in ferredoxins [24]. Similar to iron-sulfur clusters, cobalamin, known as vitamin B12, can also function as redox enzyme cofactors [25]; a typical example is the cobalamin-mediated biodegradation of chloroform by the methanogenic consortium obtained from an anaerobic distillery waste water treatment plant [26]. Riboflavin, the redox active moiety of flavin adenine dinucleotide (FAD) and flavin mononucleotide (FMN), has been shown to be differentially induced in response to furfural challenge during ethanol production by S. cerevisiae [27]. Broadly, these results support the idea that induction of genes encoding redox proteins and cofactors and transformation of furfural 

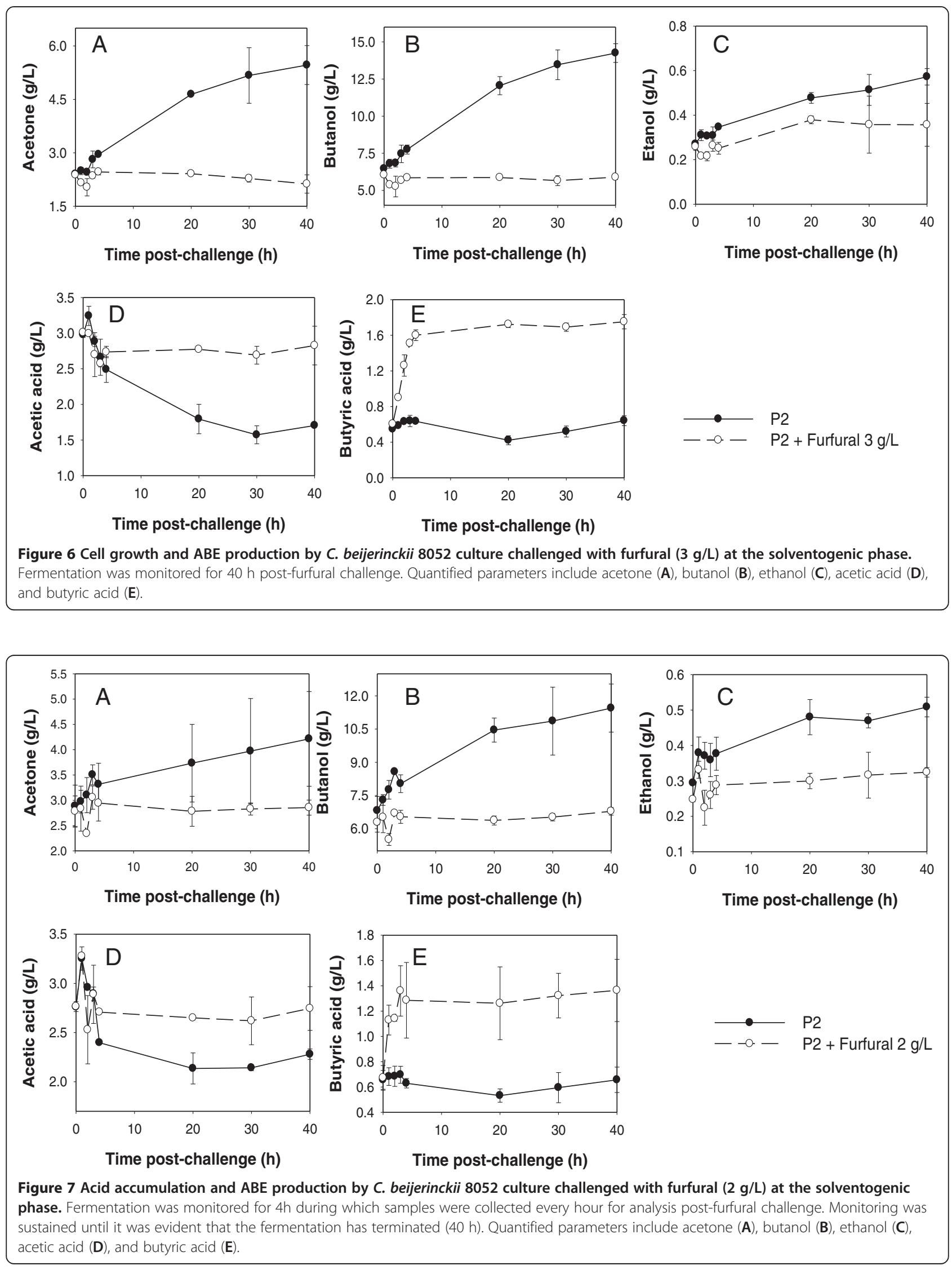


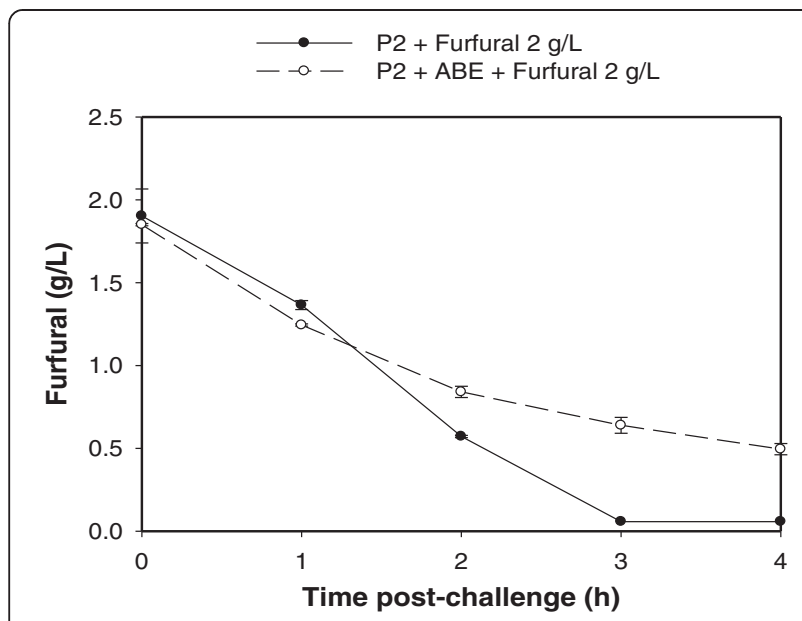

Figure 8 Reduction of furfural by acidogenic C. beijerinckii 8052 culture challenged with furfural $(2 \mathrm{~g} / \mathrm{L})$, acetone $(2.80 \mathrm{~g} / \mathrm{L})$, ethanol $(0.15 \mathrm{~g} / \mathrm{L})$ and butanol $(5.53 \mathrm{~g} / \mathrm{L})$ to bring the final concentrations of acetone, ethanol, and butanol in the fermentation broth to 3.40 $\mathrm{g} / \mathrm{L}, 0.22 \mathrm{~g} / \mathrm{L}$, and $5.93 \mathrm{~g} / \mathrm{L}$, respectively.

to less toxic furfuryl alcohol are important mechanisms that $C$. beijerinckii 8052 uses to restore redox balance under furfural stress and mitigation of toxic effects of furfural on the cell.

\section{Membrane transporter genes play active role in furfural tolerance and detoxification by C. beijerinckii 8052}

Fluctuations in differential expressions of the membrane transport system, including ATP-binding cassette transporters (ABC-transporter) and phosphotransferase system (PTS), signify possible physiological adaptations in $C$. beijerinckii 8052 in response to furfural stress (Figure 1B). The increased expression of sulfate $\mathrm{ABC}$ transporter genes (Figure 1B) in C. beijerinckii 8052 may be interpreted following a previously proposed model in E. coli [28] in which furfural depresses sulfur assimilation with concomitant inhibition of cell growth, but supplementing the fermentation medium with sulfur-containing amino acids (cysteine and methionine) reversed cell growth and increased cell tolerance to furfural. It is plausible that under furfural stress, C. beijerinckii 8052 may sense sulfur limitation and consequently elevate expression of sulfate $A B C$ transporter genes in preparation for potential increased absorption of sulfur from the fermentation medium. It is important to note that there are sulfates $\left(\mathrm{MgSO}_{4}, \mathrm{MnSO}_{4}\right.$, and $\mathrm{FeSO}_{4}$ ) in the $\mathrm{P} 2$ growth medium.

The expression of the phosphate-specific transport (Pst) system in C. beijerinckii 8052 was significantly enhanced under furfural stress (Figure $1 \mathrm{~B}$ and Additional file 1: Table S4A). Phosphate is an essential component of nucleotides; hence, it plays a central role in chemical energy and DNA/RNA synthesis. The elevated expression of the Pst system may indicate shortage of intracellular phosphates, thus, the need for increased absorption of phosphorus from the environment. Elsewhere, while Pst in E. coli was demonstrated to have decreased expression in the presence of excessive inorganic phosphate, phosphate limitation induces the expression of Pst [29]. Similarly, elevated expression of multiple operons encoding $\mathrm{ABC}$ transporters for branched-chain amino acid transportation was observed (Figure 1B and Additional file 1: Table S4A and S4C). It is conceivable that the biosynthesis of branched-chain amino acids (leucine, isoleucine and valine) in C. beijerinckii 8052 is perturbed when furfural is present in the medium, hence, the induction of genes encoding a related membrane transportation system to mitigate the perturbation. This line of reasoning agrees with the fact that furfural induces the accumulation of reactive oxygen species and superoxide anions, which may damage the synthesis of amino acids, especially the branched chain amino acids [30]. Therefore, it is reasonable that C. beijerinckii 8052 increases the expression of these $\mathrm{ABC}$ transporters to facilitate enhanced absorption of exogenous amino acids.

In contrast to $\mathrm{ABC}$ transporters, the phosphotransferase system (PTS) reveals decreased expression in furfuralchallenged C. beijerinckii 8052 (Figure 1B and Additional file 1: Table S4B and S4D). Since the bacterial PTS plays crucial roles in sugar reception, transport and phosphorylation in addition to regulation of catabolic pathways [31], the expression level of PTS may reflect the physiological state of cell metabolism and, consequently, could rationalize the low $\mathrm{ABE}$ production and premature termination of the C. beijerinckii 8052 fermentation process after furfural challenge at the solventogenic growth phase (Figures 5, 6, 7).

\section{Furfural influences the adaptation machinery of $C$. beijerinckii 8052}

The two-component signal transduction system (TCS) is a stimulus-response coupling signal transduction machinery that allows bacteria to respond and adapt to changes in a wide range of environmental conditions, such as nutrient assimilation [32], cellular redox state [33] and bacterial virulence regulation [34]. Chemotaxis, controlled by TCS, is the cells' response to stressful environments. In chemotaxis, signals are first sensed by transmembrane receptors known as methyl-accepting chemotaxis proteins (MCPs), which control the autophosphorylation of a kinase protein and then a regulator protein. The regulator protein interacts directly with flagellar proteins that act as motor switches and, thus, controls the swimming pattern of the bacterial cell [35]. Exposure of C. beijerinckii 8052 to furfural stress elicits repression of genes that code for MCPs, CheA, CheY, and flagellar proteins (Figure 1C), plausibly causing temporary (at the acidogenic phase) and permanent (at the solventogenic phase) defects in the adaptation machinery of C. beijerinckii 8052 . 
In bacteria, the carbon storage regulator (CsrA) is recognized as an activator of glycolysis, acetate metabolism, and flagellum biosynthesis [36] and as a global regulator of bacterial virulence and stress response [37]. E. coli $\operatorname{csr} A^{-}$(csrA deficient) strains are known to have severe growth problems due to central carbon stress [38], and the $\operatorname{csr} A^{-}$strain of Helicobacter pylori significantly attenuates its virulence [37]. In the presence of furfural, the global regulator CsrA in C. beijerinckii 8052 was significantly repressed (Figure $1 \mathrm{C}$ and Additional file 1: Table S4B and S4D), which may result in the repression of glycolysis and consequently, may trigger repertoires of transformations in stationary-phase physiology [38]. This could rationalize the low ABE production and premature termination of the $C$. beijerinckii 8052 fermentation process following furfural challenge at the solventogenic growth phase (Figures 5, 6, 7).

Furthermore, repression of glutamine synthetase (GS) in $C$. beijerinckii 8052 during $\mathrm{ABE}$ fermentation in the presence of furfural may decrease the production of glutamine, which may have undesirable effects with respect to nutrient assimilation and cellular redox balance. The GS strain (glutamine-requiring strain) of Bacillus subtilis was found to cause pleiotropic effects on glucose catabolite repression [39]. Moreover, glutamine is a precursor of glutamate, which may be used to synthesize glutathione, an important cellular antioxidant (albeit in reduced form) that mitigates stresses [40]. Since the product of GS plays an important role in cellular redox balance, the repression of GS may impair the tolerance of $C$. beijerinckii 8052 to furfural.

\section{Basis for both stimulatory and inhibitory effects of furfural on C. beijerinckii 8052}

Addition of furfural $(<3 \mathrm{~g} / \mathrm{L})$ to the fermentation medium inhibits ABE production by C. beijerinckii 8052 to various degrees regardless of the growth stage (acidogenic or solventogenic) of the culture (Figures 3 and 5). While $C$. beijerinckii 8052 challenged with furfural during the acidogenic phase experienced short-term ABE production inhibition (Figure 3), rapid depletion of furfural in the fermentation medium (Figure 3G), full recovery even with elevated cell growth (data not shown), and increase in $\mathrm{ABE}$ production following exhaustion of furfural in the growth medium (Figure 4), C. beijerinckii 8052 challenged with furfural at the solventogenic growth phase resulted in immediate termination of ABE fermentation (Figures 5 and 6). This finding partly agrees with previous investigations [2,7], which reported that furfural could stimulate growth and $\mathrm{ABE}$ production when added at the beginning of fermentation, but it also expands knowledge in the field by uncovering the fact that furfural is most toxic to $C$. beijerinckii 8052 during the solventogenic growth phase.
C. beijerinckii 8052 did not recover from the toxic effect of furfural when it was challenged with it at the solventogenic growth phase, yet why does furfural enhance growth of $C$. beijerinckii 8052 when it is added either at the beginning of fermentation or during the acidogenic growth phase? The answer may be found in the genes. Genes GrpE, DnaK and DnaJ in DnaK operon encoding GrpE, DnaK and DnaJ proteins are induced under furfural stress (Additional file 1: Table S4A), and they play an important role in mitigating harmful effects of environmental stresses such as UV irradiation [41], ethanol [42], and butanol [43] on microorganisms, and stresses on the cellular chaperone machinery [44]. While GroES and GroEL in the groE operon [which are also highly conserved molecular chaperons and are known to be induced by the presence of butanol [45] were differentially induced by more than threefold when C. beijerinckii 8052 was challenged with furfural during the solventogenic growth phase (Additional file 1: Table S4C), the operon was differentially induced by less than threefold when $C$. beijerinckii 8052 was challenged with furfural during the acidogenic growth phase (Additional file 1: Table S4A). Notably, overexpression of groES and groEL increases production of $\mathrm{ABE}$, tolerance to toxic products, and metabolism in solventogenic Clostridium species [45], but their increased expression during the solventogenic phase was perhaps to overcome (albeit increased expression was not enough to overcome furfural toxicity) the high toxicity of furfural to $C$. beijerinckii 8052 at this physiological growth phase.

Then, why is furfural more toxic to $C$. beijerinckii 8052 during the solventogenic phase than during the acidogenic phase? Three hypotheses are proposed. First, the presence of $\mathrm{ABE}$ enhances cell membrane fluidity and inhibits cell metabolism [46], which leads to significant loss of cell functions and weakening of the cellular defense system to furfural. This was underscored by the fact that $C$. beijerinckii 8052 was unable to completely reduce $2 \mathrm{~g} / \mathrm{L}$ furfural in the presence of $\mathrm{ABE}$ during acidogenic growth phase, unlike the control without $\mathrm{ABE}$, which reduced the entire amount of furfural (Figure 8). Second, the biotransformation of furfural, which is catalyzed by $\mathrm{NAD}(\mathrm{P}) \mathrm{H}$-dependent oxidoreductase [7], competes with $\mathrm{NAD}(\mathrm{P}) \mathrm{H}$-dependent dehydrogenase (that catalyzes alcohol production) for $\mathrm{NAD}(\mathrm{P}) \mathrm{H}$ coenzymes [47]. The need for NAD(P)H by NAD(P)H-dependent oxidoreductase to boost cellular defense against furfural is a high priority, which leads to a decrease in the NAD $(\mathrm{P}) \mathrm{H}$ pool and subsequently impedes alcohol production by NAD(P)H-dependent dehydrogenase. This hypothesis is supported by a previous finding in ethanologenic $E$. coli $[20,48]$, wherein silence of an oxidoreductase involved in furfural conversion relieves the diversion of $\mathrm{NAD}(\mathrm{P}) \mathrm{H}$ away from other important biosynthetic processes, thus, 
increasing cell growth and furfural tolerance. Competition between oxidoreductase and alcohol dehydrogenase for $\mathrm{NAD}(\mathrm{P}) \mathrm{H}$ is severe at the solventogenic growth phase, during which $\mathrm{NAD}(\mathrm{P}) \mathrm{H}$ is needed for the conversion of butyryl-CoA to butyrylaldehyde and subsequently to butanol, unlike the acidogenic growth phase, during which acids are produced in tandem with $\mathrm{NAD}(\mathrm{P}) \mathrm{H}$ production [46]. Third, while furfural repressed the expression of only two genes involved in cell motility by more than threefold when C. beijerinckii 8052 was challenged with furfural during the acidogenic phase, more than forty genes were differentially repressed by up to 18 -fold when $C$. beijerinckii 8052 was challenged with furfural at the solventogenic phase (Figure $1 \mathrm{C}$ and Additional file 1: Table S4B and S4D). Notably, the non-motile strain of C. acetobutylicum has been shown to produce lower $\mathrm{ABE}$ than the motile parent strain [49].

\section{Conclusions}

While elevated expression of redox and cofactor genes, heat shock genes, and redox balancing may contribute to enhanced ABE fermentation when C. beijerinckii 8052 was challenged with furfural at the acidogenic phase, stresses emanating from $\mathrm{ABE}$ production; redox balance perturbations; and repression of genes that code for the phosphotransferase system, cell motility and flagellar proteins (and combinations thereof) may have caused the premature termination of $C$. beijerinckii 8052 growth and $\mathrm{ABE}$ production following furfural challenge at the solventogenic phase. Transcriptomic and fermentation studies carried out in this work provided a new multifarious basis for both stimulatory and inhibitory effects of furfural on C. beijerinckii 8052 during ABE fermentation. Collectively, this study provided insights that could form the basis for metabolic engineering of $C$. beijerinckii NCIMB 8052 for enhanced tolerance of lignocellulosederived microbial inhibitory compounds, thereby improving bioconversion of lignocellulosic biomass hydrolysates to biofuels and chemicals. Indeed, we have successfully overexpressed Cbei_3974 and Cbei_3904 genes belonging to aldo/keto reductase (AKR) and short-chain dehydrogenase/reductase (SDR) families in C. beijerinckii NCIMB 8052, and generated furfural tolerant strains. Detailed physiological and biochemical characterization of developed strains are currently being conducted in our laboratory.

\section{Materials and methods}

\section{Bacterial strains, culture conditions}

C. beijerinckii NCIMB 8052 (ATCC 51743) was obtained from the American Type Culture Collection (Manassas, VA) and was used in all experiments unless noted otherwise. Stocks of $C$. beijerinckii 8052 spores were stored in sterile, double-distilled water at $4^{\circ} \mathrm{C}$. To revive $C$. beijerinckii 8052 spores, $200 \mu \mathrm{L}$ stock was heat-shocked for $10 \mathrm{~min}$ at $75^{\circ} \mathrm{C}$ followed by cooling on ice. The heatshocked spores were inoculated into $10 \mathrm{~mL}$ anoxic presterilized tryptone-glucose-yeast extract (TGY) medium and incubated in an anaerobic chamber (Coy Laboratory Products Inc., Ann Arbor, Michigan) with a modified atmosphere of $82 \% \mathrm{~N}_{2}, 15 \% \mathrm{CO}_{2}$, and $3 \% \mathrm{H}_{2}$ for $12 \mathrm{~h}$ to $14 \mathrm{~h}$ at $35^{\circ} \mathrm{C} \pm 1^{\circ} \mathrm{C}$ until active growth $\left(\mathrm{OD}_{600} 0.9-1.1\right)$ was attained [50].Eight milliliters of actively growing culture was subsequently transferred into $92 \mathrm{~mL}$ of anoxic TGY medium. The culture was grown anaerobically at $35^{\circ} \mathrm{C} \pm 1^{\circ} \mathrm{C}$ for $4 \mathrm{~h}$ to $5 \mathrm{~h}$; during this time it reached an optical density $\left(\mathrm{OD}_{600}\right)$ of $0.9-1.1$. This was used as the pre-culture.

\section{Furfural-challenged experiments and $A B E$ fermentation}

Batch ABE fermentation by C. beijerinckii 8052 was performed in 250-mL Pyrex screw-capped media bottles containing $200 \mathrm{~mL}$ anoxic P2 medium (glucose $60 \mathrm{~g} / \mathrm{L}$ and yeast extract $1 \mathrm{~g} / \mathrm{L}$ ) and P2 stock solutions as described previously [7].

To evaluate the response of $C$. beijerinckii 8052 to furfural during acidogenic and solventogenic phases, a 1-L flask containing $600 \mathrm{~mL}$ anoxic P2 medium plus P2 stock solutions was inoculated $(6 \% \mathrm{v} / \mathrm{v})$ with C. beijerinckii 8052 pre-culture and incubated anaerobically for $8 \mathrm{~h}$; during this time the $\mathrm{OD}_{600}$ attained $1.4 \pm 0.05$ (acidogenic phase). The culture was then subdivided into aliquots of $100 \mathrm{~mL}$ in six 150-mL Pyrex screw-capped media bottles. Three bottles in the treatment group were challenged with furfural $(2 \mathrm{~g} / \mathrm{L})$ and the other three bottles were left unchallenged as the control. After 2 to $3 \mathrm{~h}$ growth at $35^{\circ} \mathrm{C}$, the original concentration of furfural in the growth medium was reduced by more than half, and C. beijerinckii 8052 samples were collected from each bottle and triplicate control and furfural-challenged samples were pooled separately. Notably, cell density of $C$. beijerinckii 8052 during solventogenic phase was markedly higher than that at acidogenic growth phase. Given the greater number of C. beijerinckii 8052 cells in the fermentation medium at solventogenic phase; we decided to increase the concentration of furfural to $3 \mathrm{~g} / \mathrm{L}$. For furfural challenge at solventogenic phase, $600 \mathrm{ml}$ of C. beijerinckii 8052 culture was incubated anaerobically for $24 \mathrm{~h}$; during this time the $\mathrm{OD}_{600}$ attained $4.0 \pm 0.2$, and then subdivided into aliquots of $100 \mathrm{~mL}$ in six $150-\mathrm{mL}$ bottles. Three bottles were challenged with $3 \mathrm{~g} / \mathrm{L}$ of furfural which were the treatment group and the other three bottles were unchallenged (control). Following 2 to $3 \mathrm{~h}$ post-furfural challenge, during which time the original concentration of furfural in the growth medium was reduced by more than half, C. beijerinckii 8052 samples were collected from each bottle and triplicate control and furfural-challenged samples were pooled separately for analysis. Aliquots of $C$. beijerinckii 8052 samples were placed on ice immediately 
after removal from the bottles. C. beijerinckii 8052 pellets were obtained by centrifugation at $5000 \mathrm{~g}$ for $10 \mathrm{~min}$ at $4^{\circ} \mathrm{C}$ prior to suspension in a solution containing a $2: 1$ ratio of RNAprotect cell reagent to phosphate-buffered saline (PBS) (Qiagen Inc., Valencia, CA) to stabilize the RNA. The suspension was incubated at room temperature for 5 min, centrifuged to obtain cell pellets, and stored at $-80^{\circ} \mathrm{C}$ overnight as described previously [51].

The $\mathrm{pH}$ profile of $C$. beijerinckii 8052 fermentation was monitored with a Beckman $\Phi 500$ pH meter (Beckman Coulter Inc., Brea, CA). Growth of C. beijerinckii 8052 was estimated using a DU800 spectrophotometer (Beckman Coulter Inc., Brea, CA) to measure the $\mathrm{OD}_{600}$. Concentrations of fermentation products-acetate, butyrate, acetone, butanol, and ethanol were measured using a 7890A Agilent Technologies gas chromatograph (Agilent Technologies Inc., Wilmington, DE) equipped with a flame ionization detector (FID) and $30 \mathrm{~m}$ (length) $\times 320 \mathrm{~m}$ (internal diameter $\times 0.50 \mathrm{~m}(\mathrm{HP}-$ Innowax film $) \mathrm{J} \times \mathrm{W} 19091 \mathrm{~N}-213 \mathrm{ca}-$ pillary column as described previously [50]. Initial and residual furfural concentrations in the growth medium were determined as described previously [7].

\section{Total RNA purification}

The total cellular RNA was purified from $2 \mathrm{~mL} C$. beijerinckii 8052 culture. Briefly, C. beijerinckii 8052 cell pellets from $2 \mathrm{~mL}$ culture aliquots were thawed on ice and re-suspended in the addition of $750 \mu \mathrm{L}$ RLT buffer ${ }^{\mathrm{TM}}$ (Qiagen Inc., Valencia, CA) supplemented with $1 \%(\mathrm{v} / \mathrm{v})$ $\beta$-mercaptoethanol ( $\beta$ - ME). For complete lysis of $C$. beijerinckii 8052, a $2 \mathrm{~mL}$ microcentrifuge tube was half filled with $0.1 \mathrm{~mm}$ diameter zirconia/silica beads (Biospec, Bartlesville, OK) followed by $750 \mu \mathrm{L}$ RLT buffer ${ }^{\text {TM }}$ supplemented with $1 \%(\mathrm{v} / \mathrm{v}) \beta-\mathrm{ME}$ and then chilling on ice. $C$. beijerinckii 8052 suspension $(750 \mu \mathrm{L})$ was added to the pre-chilled tube with beads and agitated in a TissueLyser LT (Qiagen Inc., Valencia, CA) for $8 \mathrm{~min}$ at a setting of $50 \mathrm{~Hz}$ to break the C. beijerinckii 8052 cells. Total RNA was purified from homogenized cells using an RNeasy mini kit (Qiagen Inc., Valencia, CA) according to the manufacturer's instructions. RNA quality was analyzed using a Nanochip 2100 bioanalyzer (Agilent Technologies Inc., Wilmington, DE), and RNA concentration was measured by NanoDrop 3300 (Thermo scientific, Wilmington, DE) according to the manufacturer's instructions.

\section{Comparative microarray hybridization}

The microarray was constructed by MYcroarray Inc. (Ann Arbor, MI) [52,53]. A total of 5,003 C. beijerinckii NCIMB 8052 genes capturing about $99.7 \%$ of the genome were examined. To minimize error, five identical replicates of each C. beijerinckii 8052 probe sequence (45-47mer) were designed and fabricated onto the microarray chip. To enhance hybridization, $10 \mu \mathrm{g}$ of total RNA was converted to enriched mRNA using a MICROBExpress ${ }^{\mathrm{TM}}$ Bacterial mRNA Enrichment Kit (Life Technologies, Grand Island, NY) and following manufacturer's protocol. About $200 \mathrm{ng}$ of enriched mRNA was converted to complementary RNA (cRNA) using a MessageAmp ${ }^{\mathrm{TM}}$ II-Bacteria RNA Amplification Kit (Life Technologies, Grand Island, NY) and following manufacturer's protocol. Alexa Fluor 555 (Life Technologies, Grand Island, NY) was coupled to cRNA following the manufacturer's instructions. Removal of unincorporated dye was conducted using RNeasy Mini Columns (Qiagen Inc., Valencia, CA) and following manufacturer's protocol. About $30-50 \mu \mathrm{L}$ eluate containing $\sim 40 \mu \mathrm{g}$ labeled cRNA was generated. The resulting dyecoupled cRNA was made up to $60 \mu \mathrm{L}$ with $2 \mu \mathrm{L} 150 \mathrm{mM}$ $\mathrm{ZnSO}_{4}$ and elution buffer to bring the final concentration of $\mathrm{ZnSO}_{4}$ to $5 \mathrm{mM}$; this dilution was followed by incubation (fragmentation) at $75^{\circ} \mathrm{C}$ for $10 \mathrm{~min}$. Ten micrograms of each fluor-labeled cRNA was hybridized separately to one array, and hybridization was performed for $20 \mathrm{~h}$ at $45^{\circ} \mathrm{C}$ in a hybridization buffer containing 6x SSPE (20X SSPE stock: $3 \mathrm{M} \mathrm{NaCl}, 20 \mathrm{mM}$ EDTA, $118.2 \mathrm{mM}$ $\mathrm{NaH}_{2} \mathrm{PO}_{4}$ and $81.8 \mathrm{mM} \mathrm{Na}_{2} \mathrm{HPO}_{4}$ ), 10\% de-ionized formamide, $0.01 \mathrm{mg} / \mathrm{mL}$ acetylated BSA, 0.01\% Tween-20, and $1 \%$ control oligos (provided by Mycroarray Inc). After hybridization, the slide was washed with fresh $6 \mathrm{x}$ SSPE buffer $\left(24^{\circ} \mathrm{C}\right)$ and transferred to fresh $0.5 \times$ SSPE buffer prior to drying. The slide was dried immediately by centrifugation at $2000 \mathrm{~g}$ for $3 \mathrm{~min}$ prior to scanning by an Axon 4000B Scanner (Molecular Devices, Sunnyvale, CA).

\section{Microarray data analysis}

The slide was scanned using an Axon 4000B Scanner set at $5 \mu \mathrm{m}$ per pixel resolution and $100 \%$ laser power. The scanned images were extracted and analyzed using version 6.1.0.4 GenePix Pro Software (Molecular Devices, Sunnyvale, CA). For signal extraction, circular feature indicators (35 $\mu \mathrm{m}$ diameter) were centered over each spot, and the median feature pixel intensity was extracted. Data images were extracted from the center of the spot area (35 $\mu \mathrm{m}$ in diameter), where the sequence fidelity is exceptional, instead of from the larger indicator feature spot diameter area $(\sim 60 \mu \mathrm{m})$. To minimize error due to differences in sample behavior from array to array, a scale factor was created to normalize the signal across all arrays. A scale factor (SF) for each array was calculated as follows:

$$
\begin{aligned}
\mathrm{SF}= & \mu\left({\text { median pixel signal })_{\text {control }} /} /\right. \\
& \mu(\text { median pixel signal })_{\text {treatment }}
\end{aligned}
$$

Trimmed mean was used to generate the final signal value for the five identical probe replicates, which identified the differential expression pattern of each gene on the array. The trimmed mean was calculated by discarding the maximum and minimum adjusted signal within each set 
of five probe replicates, followed by averaging the adjusted signal values of the remaining three probes. Relative expression levels (gene expression ratio) for each gene were calculated by dividing the signal intensity of the array from the furfural-challenged C. beijerinckii 8052 culture by the intensity of the unchallenged control culture. To facilitate a fair comparison of up- and down-regulated genes, fold change was calculated as follows: for genes with an expression ratio $\geq 1$, the fold change is the same as the expression ratio, whereas folds change of genes whose expression ratio is $<1$ equals the reciprocal of the expression ratio multiplied by -1 [54]. To make data distribution symmetrical, the gene expression ratio was used to calculate the $\log 2$ transformation ratio as described previously [55]. Expression patterns were visualized colorimetrically using TreeView (version 1.60). Enrichment analysis of Gene Ontology terms, including biological process, cellular component and molecular function, and KEGG (Kyoto Encyclopedia of Genes and Genomes) enrichment pathway analysis were performed using a DAVID Functional Annotation Bioinformatics Microarray analysis to identify statistically over-represented biological terms [56].

\section{Microarray data accession number}

All protocols related to this microarray platform, which include information on probe sequences and synthesis, labeling, hybridization and scan protocols, and microarray data have been submitted to NCBI's Gene Expression Omnibus database at http://www.ncbi.nlm.nih.gov/ geo/ with GEO accession number GSE42597.

Real-time quantitative reverse transcription PCR (Q-RT-PCR) Following microarray analysis, several genes were differentially induced or repressed in response to furfural stress, and several genes were selected for further analysis using Q-RT-PCR to validate microarray results. Briefly, C. beijerinckii 8052 cultures were grown anaerobically and challenged with $2-3$ g/L furfural during acidogenic and solventogenic growth phases followed by centrifugation to collect cell pellets as described above. Total RNA was purified from cell pellets of furfuralchallenged and unchallenged C. beijerinckii 8052 cultures and lysed with TissueLyser LT as described above. Genomic DNA was removed from the total RNA isolate using RNase-free DNase (New England Biolabs Inc, Ipswich, MA). Total RNA $(2 \mu \mathrm{g})$ was reverse transcribed to form first strand cDNA by random hexamer-primed reverse transcription reactions using SuperScript III reverse transcriptase (Life Technologies, Grand Island, NY) following the manufacturer's instructions. For quantitative reverse transcription polymerase chain reaction (Q-RT-PCR), cDNA, specific primers and $\mathrm{GoTaq}^{\circledR}$ qPCR Master Mix containing Bryt ${ }^{\mathrm{T} \mathrm{M}}$ Green dye (Promega, Madison, WI) were proportionately mixed following manufacturer's protocol.
The forward and reverse gene-specific primers used for amplification of specific genes were synthesized by Eurofins MWG Operon and are listed in Additional file 4: Table S1. The 16S rRNA of $C$. beijerinckii 8052, which was amplified with gene-specific forward (5'- GAA GAA TAC CAG TGG CGA AGG C-3') and reverse (5'- ATT CAT CGT TTA CGG CGT GGA C-3') primers, was used as the internal standard. Prior to selection of $16 \mathrm{~S}$ rRNA as an internal standard, the expression of 16s rRNA of furfuralchallenged and unchallenged C. beijerinckii 8052 cultures was analyzed and confirmed for constant expression under the reaction condition of the study. The mRNA levels of genes of interest (Additional file 4: Table S1) were quantified by subjecting cDNA to Q-RT-PCR analysis in triplicate samples using a Bio-Rad iCycler continuous fluorescence detection system (Bio-Rad, Hercules, CA). The Q-RT-PCR reaction conditions were as follows: step $1,95^{\circ} \mathrm{C}$ for $2 \mathrm{~min}$ (hot-start activation), step $2,95^{\circ} \mathrm{C}$ for $15 \mathrm{sec}$ (denaturation), step $3,55^{\circ} \mathrm{C}$ for $30 \mathrm{sec}$ (annealing and extension), 40 cycles of step 2 and 3 , step $4,95^{\circ} \mathrm{C}$ for $1 \mathrm{~min}$ (denature of PCR product), step $5,55^{\circ} \mathrm{C}$ for 1 min (annealing of PCR product), and step 6 , heat from $65^{\circ} \mathrm{C}$ to $95^{\circ} \mathrm{C}$ with a ramp speed of $1^{\circ} \mathrm{C}$ per $10 \mathrm{sec}$, resulting in melting curves. Expression levels of C. beijerinckii 8052 genes were quantified by the comparative $\mathrm{C}_{\mathrm{T}}$ method as previously described [57].

\section{Additional files}

Additional file 1: Table S4. Genes up- and down-regulated by more than 3 folds during acidogenic furfural-challenge.

Additional file 2: Table S2A. Enriched up- and down-regulated Gene Ontology Groups in the experiment of furfural challenge during acidogenesis.

Additional file 3: Table S3. Significantly regulated KEGG classifications during furfural challenge experiment.

Additional file 4: Table S1. List of 30 genes and sequences of primers used in validation of microarray analysis by Q-RT-PCR.

Additional file 5: Table S5. Fold change of solvent production genes according to microarray analysis.

\section{Abbreviations}

ATCC: American Type Culture Collection; DNA: Deoxyribonucleic acid; GC: Gas chromatography; HPLC: High pressure liquid chromatography; $\mathrm{NAD}^{+}$: Nicotinamide adenine dinucleotide; NADH: Nicotinamide adenine dinucleotide, reduced; NADP $^{+}$: Nicotinamide adenine dinucleotide phosphate; NADPH: Nicotinamide adenine dinucleotide phosphate, reduced; PCR: Polymerase chain reaction; Q-RT-PCR: Quantitative real-time polymerase chain reaction; RNA: Ribonucleic acid.

\section{Competing interests}

The authors declare that they have no competing interests.

\section{Authors' contributions}

YZ conducted the work presented here, performed data analysis and drafted the manuscript. YZ and TCE contributed to data interpretation, wrote and revised the manuscript. TCE conceived, designed and coordinated the study. All authors read and approved the final manuscript.

\section{Acknowledgments}

Research support was provided in part by state and federal funds appropriated to The Ohio State University, Ohio Agricultural Research and 
Development Center, and the Hatch grant (Project No. OHO01222). We are grateful to Dr. Siqing Liu (Research Molecular Biologist, Renewable Product Technology Research, NCAUR-ARS-USDA, Peoria, Illinois) and Ms. Michelle Hendrick (Department of Animal Sciences, The Ohio State University) for reading this manuscript and providing critical comments.

Received: 1 December 2012 Accepted: 29 April 2013

Published: 4 May 2013

\section{References}

1. Mitchell WJ: Physiology of carbohydrate to solvent conversion by clostridia. Adv Microb Physiol 1997, 39:31-130.

2. Ezeji TC, Qureshi N, Blaschek HP: Butanol production from agricultural residues: Impact of degradation products on Clostridium beijerinckii growth and butanol fermentation. Biotechnol Bioeng 2007, 97(6):1460-1469.

3. Mills TY, Sandoval NR, Gill RT: Cellulosic hydrolysate toxicity and tolerance mechanisms in Escherichia coli. Biotechnol Biofuels 2009, 2(1):26

4. Allen SA, Clark W, McCaffery JM, Cai Z, Lanctot A, Slininger PJ, Liu ZL, Gorsich SW: Furfural induces reactive oxygen species accumulation and cellular damage in Saccharomyces cerevisiae. Biotechnol Biofuels 2010, 3:2.

5. Liu ZL, Blaschek HP: Biomass conversion inhibitors and in situ detoxification. In Biomass to Biofuels: Strategies for Global Industries. Edited by Vertès AA, Oureshi A, Blaschek HP, Yukawa H. West Sussex, United Kingdom: Wiley; 2010:233-259.

6. Qureshi N, Bowman M, Saha B, Hector R, Berhow M, Cotta M: Effect of cellulosic sugar degradation products (furfural and hydroxymethyl furfural) on acetone-butanol-ethanol (ABE) fermentation using Clostridium beijerinckii P260. Food Bioprod Process 2011, 90:533-540.

7. Zhang Y, Han B, Ezeji TC: Biotransformation of furfural and 5hydroxymethyl furfural (HMF) by Clostridium acetobutylicum ATCC 824 during butanol fermentation. N Biotechnol 2012, 29(3):345-351.

8. Ezeji TC, Blaschek HP: Fermentation of dried distillers' grains and solubles (DDGS) hydrolysates to solvents and value-added products by solventogenic clostridia. Bioresour Technol 2008, 99(12):5232-5242.

9. Armitage JP, Schmitt R: Bacterial chemotaxis: Rhodobacter sphaeroides and Sinorhizobium meliloti - variations on a theme? Microbiology 1997 143:3671-3682.

10. Etienne W, Meyer MH, Peppers J, Meyer RA: Comparison of mRNA gene expression by RT-PCR and DNA microarray. Biotechniques 2004, 36(4):618-627

11. Morey JS, Ryan JC, Van Dolah FM: Microarray validation: factors influencing correlation between oligonucleotide microarrays and real-time PCR. Biol Proc Online 2006, 8(1):175-193.

12. Veal EA, Day AM, Morgan BA: Hydrogen peroxide sensing and signaling. Mol Cell 2007, 26(1):1-14

13. Zeller T, Klug G: Thioredoxins in bacteria: functions in oxidative stress response and regulation of thioredoxin genes. Naturwissenschaften 2006 93(6):259-266

14. Bisby RH, Morgan CG, Hamblett I, Gorman AA: Quenching of singlet oxygen by trolox $\mathrm{C}$, ascorbate, and amino acids: effects of $\mathrm{pH}$ and temperature. J Phys Chem A 1999, 103(37):7454-7459.

15. Kullisaar T, Zilmer M, Mikelsaar M, Vihalemm T, Annuk H, Kairane C, Kilk A: Two antioxidative lactobacilli strains as promising probiotics. Int $\mathrm{J}$ Food Microbiol 2002, 72(3):215-224

16. Rocha ER, Smith CJ: Role of the alkyl hydroperoxide reductase (ahpCF) gene in oxidative stress defense of the obligate anaerobe Bacteroides fragilis. J Bacteriol 1999, 181(18):5701-5710.

17. Cha M, Kim W, Lim C, Kim K, Kim I: Escherichia coli periplasmic thiol peroxidase acts as lipid hydroperoxide peroxidase and the principa antioxidative function during anaerobic growth. J Biol Chem 2004, 279(10):8769-8778

18. Zheng Z, Chen T, Zhao M, Wang Z, Zhao X: Engineering Escherichia coli for succinate production from hemicellulose via consolidated bioprocessing Microb Cell Fact 2012, 11(1):37.

19. Arnér ESJ, Holmgren A: Physiological functions of thioredoxin and thioredoxin reductase. Eur J Biochem 2000, 267(20):6102-6109.

20. Miller EN, Jarboe L, Yomano L, York S, Shanmugam K, Ingram L: Silencing of NADPH-dependent oxidoreductase genes ( $y q h D$ and $d \mathrm{~kg} A$ ) in furfuralresistant ethanologenic Escherichia coli. Appl Environ Microbiol 2009, 75(13):4315-4323.
21. Jarboe LR: YqhD: a broad-substrate range aldehyde reductase with various applications in production of biorenewable fuels and chemicals. Appl Microbiol Biotechnol 2011, 89(2):249-257.

22. Liu ZL, Moon J, Andersh BJ, Slininger PJ, Weber S: Multiple gene-mediated NAD (P) H-dependent aldehyde reduction is a mechanism of in situ detoxification of furfural and 5-hydroxymethylfurfural by Saccharomyces cerevisiae. Appl Microbiol Biotechnol 2008, 81(4):743-753.

23. Agrawal $M$, Chen RR: Discovery and characterization of a xylose reductase from Zymomonas mobilis ZM4. Biotechnol Lett 2011, 33:2127-2133.

24. Johnson DC, Dean DR, Smith AD, Johnson MK: Structure, function, and formation of biological iron-sulfur clusters. Annu Rev Biochem 2005, 74:247-281.

25. Schumacher W, Holliger C, Zehnder AJB, Hagen WR: Redox chemistry of cobalamin and iron-sulfur cofactors in the tetrachloroethene reductase of Dehalobacter restrictus. FEBS Lett 1997, 409(3):421-425.

26. Guerrero-Barajas C, Field JA: Riboflavin-and cobalamin-mediated biodegradation of chloroform in a methanogenic consortium. Biotechnol Bioeng 2005, 89(5):539-550.

27. Li BZ, Yuan YJ: Transcriptome shifts in response to furfural and acetic acid in Saccharomyces cerevisiae. Appl Microbiol Biotechnol 2010, 86(6):1915-1924.

27. Miller EN, Jarboe LR, Turner PC, Pharkya P, Yomano LP, York SW, Nunn D, Shanmugam K, Ingram LO: Furfural inhibits growth by limiting sulfur assimilation in ethanologenic Escherichia coli strain LY180. Appl Environ Microbiol 2009, 75(19):6132-6141.

28. van Veen HW: Phosphate transport in prokaryotes: molecules, mediators and mechanisms. Antonie Van Leeuwenhoek 1997, 72(4):299-315.

29. Storz G, Tartaglia LA, Farr SB, Ames BN: Bacterial defenses against oxidative stress. Trends Genet 1990, 6:363-368.

30. Saier MH Jr: The bacterial phosphotransferase system: structure, function, regulation and evolution. J Mol Microbiol Biotechnol 2001, 3(3):325-328.

31. Görke B, Stülke J: Carbon catabolite repression in bacteria: many ways to make the most out of nutrients. Nat Rev Microbiol 2008, 6(8):613-624.

32. Fernández-Piñar R, Ramos JL, Rodríguez-Herva JJ, Espinosa-Urgel M: A twocomponent regulatory system integrates redox state and population density sensing in Pseudomonas putida. J Bacteriol 2008, 190(23):7666-7674.

33. Beier D, Gross R: Regulation of bacterial virulence by two-component systems. Curr Opin Microbiol 2006, 9(2):143-152.

34. Faguy $\mathrm{D}$, Jarrell $\mathrm{K}: \mathrm{A}$ twisted tale: the origin and evolution of motility and chemotaxis in prokaryotes. Microbiology 1999, 145(2):279-281.

35. Dubey AK, Baker CS, Suzuki K, Jones AD, Pandit P, Romeo T, Babitzke P: CsrA regulates translation of the Escherichia coli carbon starvation gene, cstA, by blocking ribosome access to the cstA transcript. J Bacteriol 2003, 185(15):4450-4460

36. Barnard FM, Loughlin MF, Fainberg HP, Messenger MP, Ussery DW, Williams $P$, Jenks PJ: Global regulation of virulence and the stress response by CsrA in the highly adapted human gastric pathogen Helicobacter pylori. Mol Microbiol 2004, 51(1):15-32.

37. Wei B, Shin S, LaPorte D, Wolfe AJ, Romeo T: Global regulatory mutations in csrA and rpoS cause severe central carbon stress in Escherichia coli in the presence of acetate. J Bacterio/ 2000, 182(6):1632-1640.

38. Fisher SH, Sonenshein AL: Bacillus subtilis glutamine synthetase mutants pleiotropically altered in glucose catabolite repression. J Bacterio/ 1984, 157(2):612-621.

39. Matés JM, Pérez-Gómez C, de Castro IN, Asenjo M, Márquez J: Glutamine and its relationship with intracellular redox status, oxidative stress and cell proliferation/death. Int J Biochem Cell Biol 2002, 34(5):439-458.

40. Krueger JH, Walker GC: groEL and dnaK genes of Escherichia coli are induced by UV irradiation and nalidixic acid in an $h t p R^{+}$-dependent fashion. Proc Natl Acad Sci 1984, 81(5):1499-1503.

41. Weng SF, Tai PM, Yang CH, Wu CD, Tsai WJ, Lin JW, Tseng YH: Characterization of stress-responsive genes, hrcA-grpE-dnaK-dnaJ, from phytopathogenic Xanthomonas campestris. Arch Microbiol 2001, 176(1):121-128.

42. Narberhaus F, Giebeler K, Bahl H: Molecular characterization of the dnaK gene region of Clostridium acetobutylicum, including grpE, dnaJ, and a new heat shock gene. J Bacteriol 1992, 174(10):3290-3299.

43. Schröder H, Langer T, Hartl F, Bukau B: DnaK, DnaJ and GrpE form a cellular chaperone machinery capable of repairing heat-induced protein damage. EMBO J 1993, 12(11):4137-4144. 
44. Tomas CA, Welker NE, Papoutsakis ET: Overexpression of groESL in Clostridium acetobutylicum results in increased solvent production and tolerance, prolonged metabolism, and changes in the cell's transcriptional program. Appl Environ Microbiol 2003, 69(8):4951-4965.

45. Ezeji T, Milne C, Price ND, Blaschek HP: Achievements and perspectives to overcome the poor solvent resistance in acetone and butanol-producing microorganisms. App/ Microbiol Biotechnol 2010, 85(6):1697-1712.

46. Tummala SB, Junne SG, Papoutsakis ET: Antisense RNA downregulation of coenzyme A transferase combined with alcohol-aldehyde dehydrogenase overexpression leads to predominantly alcohologenic Clostridium acetobutylicum fermentations. J Bacteriol 2003, 185(12):3644-3653.

47. Turner PC, Miller EN, Jarboe LR, Baggett CL, Shanmugam K, Ingram LO YqhC regulates transcription of the adjacent Escherichia coli genes yqhD and $\mathrm{dkgA}$ that are involved in furfural tolerance. $J$ Ind Microbiol Biotechnol 2011, 38(3):431-439.

48. Gutierrez N, Maddox I: Isolation and partial characterization of a nonmotile mutant of Clostridium acetobutylicum. Biotechnol Lett 1990, 12(11):853-856.

49. Han B, Gopalan V, Ezeji TC: Acetone production in solventogenic Clostridium species: new insights from non-enzymatic decarboxylation of acetoacetate. Appl Microbiol Biotechnol 2011, 91(3):565-576.

50. Servinsky MD, Kiel JT, Dupuy NF, Sund CJ: Transcriptional analysis of differential carbohydrate utilization by Clostridium acetobutylicum. Microbiology 2010, 156(11):3478-3491.

51. Yi H, Cho K, Cho YS, Kim K, Nierman WC, Kim HS: Twelve Positions in a $\beta$-Lactamase That Can Expand Its Substrate Spectrum with a Single Amino Acid Substitution. PLoS One 2012, 7(5):e37585.

52. Lemmon AR, Emme SA, Lemmon EM: Anchored hybrid enrichment for massively high-throughput phylogenomics. Syst Biol 2012, 61(5):727-744.

53. Babu MM: Introduction to microarray data analysis. In Computational Genomics: Theory and Application. Edited by Grant RP. Norwich: Horizon Press; 2004:225-249.

54. Quackenbush J: Microarray data normalization and transformation. Nat Genet 2002, 32:496-501.

55. Huang DW, Sherman BT, Lempicki RA: Systematic and integrative analysis of large gene lists using DAVID bioinformatics resources. Nat Protoc 2009, 4(1):44-57.

56. Schmittgen TD, Livak KJ: Analyzing real-time PCR data by the comparative $C_{T}$ method. Nat Protoc 2008, 3(6):1101-1108.

doi:10.1186/1754-6834-6-66

Cite this article as: Zhang and Ezeji: Transcriptional analysis of Clostridium beijerinckii NCIMB 8052 to elucidate role of furfural stress during acetone butanol ethanol fermentation. Biotechnology for Biofuels 2013 6:66.

\section{Submit your next manuscript to BioMed Central and take full advantage of:}

- Convenient online submission

- Thorough peer review

- No space constraints or color figure charges

- Immediate publication on acceptance

- Inclusion in PubMed, CAS, Scopus and Google Scholar

- Research which is freely available for redistribution 